\title{
Sexually transmitted diseases in India and Sri Lanka
}

\author{
R D CATTERALL \\ From James Pringle House, Middlesex Hospital, London
}

\section{India}

India is a vast country and is larger than the whole of Western Europe. On its 1620000 square miles of land over 650000000 people live and die. The population is believed to be increasing at a rate of more than 13 millions each year. There are over 220 different languages and many different communities and cultures, all of which are responsible for the colourful and exciting life of the nation. Because of its size generalisations about India are usually unreliable and frequently untrue.

\section{HEALTH PROBLEMS}

The major health problem is the lack of a pure water supply and the almost total absence of sewage disposal. It has been estimated by the World Health Organisation that if an adequate supply of safe water and a reasonable sewage disposal system could be provided, the mortality rate would fall by at least $50 \%$, to say nothing of the rates of acute and chronic sickness. Add to this widespread malnutrition, tropical diseases, tuberculosis, leprosy, and diarrhoeal diseases and the relatively low priority that has been given to the sexually transmitted diseases is understandable. Nevertheless, the incidence and the variety of sexually communicable diseases is increasing throughout the country and is a source of anxiety to some health authorities.

Although central government and municipal authorities play some part medical care and medical education are largely the responsibility of the state governments. Private medical practitioners, private hospitals, and even private medical colleges are to be found throughout the country. As elsewhere in the world, there are too many practitioners in the cities competing for the relatively small number of patients who can afford western medicine; primary care in the cities is frequently provided by unqualified practitioners.

\section{HEALTH CARE}

The principal problem, however, is the provision of health care in the villages and in the countryside

Address for reprints: Dr R D Catterall, James Pringle House, Middlesex Hospital, London W1

Accepted for publication 26 April 1982 rather than in the cities. Because of the striking imbalance between the number of doctors and the potential patients, the type of care is very varied and people are more likely to receive treatment from local, indigenous, traditional practitioners than from doctors trained in western medicine.

The basic unit of the state system of health care is the primary health care centre, which tries to provide modern medical facilities for a rural population. Each centre is responsible for a population of about 100000 people and is staffed by two doctors working with medical auxiliaries, who see the large majority of the patients. In reality the doctors are constantly swamped by enormous numbers of patients, and in most cases doctors devote less than five minutes to each patient and frequently only 30 to 60 seconds. All treatment is free but, as can be imagined, most doctors prefer to do private practice, if possible in an urban area.

There are rural hospitals and larger district hospitals of about 200 beds. Below a certain income level admission to hospital is free. Most of the hospitals are, however, in the towns and are managed by the civil and municipal authorities. Some of these will be university teaching hospitals.

\section{SEXUALLY TRANSMITTED DISEASES}

Patients with sexually transmitted diseases are most likely to be seen by an unregistered practitioner of traditional medicine, to treat themselves with antibiotics bought over the counter, or not to have any treatment at all. Some will be seen by general practitioners and only a minority will seek advice and treatment from a specialist.

Traditionally venereology and dermatology have formed the combined specialty of dermatovenereology, and most university teaching hospitals have a department of dermatovenereology. The one outstanding exception to this is in Madras where the two subjects are separated and the Institute of Venereology at the Government General Hospital specialises in sexually transmitted diseases. Founded by Dr R V Rajan, its traditions of high-quality patient care, teaching of both undergraduate and postgraduate medical students, and research have been maintained by its subsequent directors, Dr P N Rangiah, Dr C N Sowmini, and now Dr K Vijaycilaksmi. It is a model department, and its constitution, organisation, and 
management are an example to other centres throughout India and the world.

The Indian Association for the Study of Sexually Transmitted Diseases was founded in 1975 in Madras and has steadily increased its membership and reputation. It has now held six annual conferences and its next conference is planned to take place in Bombay in the spring of 1983 at a date to be decided later.

The separation of the specialties of dermatology and venereology is being debated in India at the present time. There is no doubt that when the specialties are combined the dermatological patients are more prized by the doctors and the venereology patients are often cared for by the more junior and less experienced members of the staff, frequently without adequate supervision and consultation. As the two subjects grow further apart it becomes increasingly difficult to keep up to date with advances in both specialties, and the skills and expertise necessary to practice the two specialties to high standards become increasingly difficult to maintain. The example of the Institute of Venereology in Madras makes it quite clear that venereology can be practised at a much higher standard if it is separated from dermatology and becomes a recognised specialty in its own right. Moreover, contact tracing and the management of social and sexual problems can be dealt with more efficiently in a department specialising solely in sexually transmitted diseases.

\section{Sri Lanka}

Sri Lanka is a beautiful island situated about 30 miles off the south-east tip of India. It is flat in the north but mountainous in the south, with central areas as high as $\mathbf{8 0 0 0}$ feet or more. The island is compact and is about 270 miles long by about 140 miles wide. There are beautiful sandy beaches, rugged cliffs, mountains, and wild jungle. Colombo, the capital, is a large city with about $2 \frac{1}{2}$ million inhabitants and is an important commercial and communication centre both by air and sea.

Sri Lanka is one of the most heavily populated countries in South-east Asia and has a total population of over 15 million inhabitants. It is a fertile island and exports tea, rubber, coconut products, cocoa, cinnamon, and timber. The general standard of living has been rising perceptibly during the past 25 years.

\section{SERVICES FOR SEXUALLY TRANSMITTED}

\section{DISEASES}

Complete independence from British rule was achieved in 1948. Shortly afterwards the report of a World Health Organisation (WHO) group on the control of venereal diseases was published. The group included Dr Sidney Laird of Britain. It recommended that the British system for the control of venereal diseases should be adopted on the island. The government accepted the report and Dr Eunice Pereira was appointed to build up the service. She was succeeded by Dr H C B Premachandra in 1972 as superintendent of the anti-VD campaign.

The service closely resembles the British service and consists of a central, model clinic in Colombo in the hospital grounds and a series of part-time clinics in the district hospitals staffed by doctors and nurses who have had some special training in STD. In outlying areas there is usually a doctor who has special knowledge of the subject, who is available to see patients and often holds one or two clinics a week.

The central clinic in Colombo is situated in a large house next to the main hospital buildings and is just adequate for the present situation, but new premises will be required in the future. There is a staff of six well-trained clinicians, all of whom are full-time venereologists, and the clinic is open all day for five days a week. The director, Dr H C B Premachandra, is well-known for his international work with the WHO and the International Union against the Venereal Diseases and Treponematoses. An excellent microbiological and serological service is provided by Dr N R W Pereira.

Both male and female nurses and contact tracers play an important part in the management of the patients. Undergraduate and postgraduate teaching is encouraged in the department and research is undertaken into many aspects of the diseases. Public health education about sexually transmitted diseases is being slowly developed and improved.

In 1980 there were about 12600 new cases seen at the clinic, of which 3065 were cases of gonorrhoea and 322 of syphilis. Herpes, non-specific urethritis, and genital warts are all being seen more frequently. $\beta$-lactamase strains of gonococci have been identified with increasing frequency and it is believed that some of the organisms are now established in the indigenous population of the island, although many strains are brought in from overseas, particularly from South-east Asia.

It is estimated that as many as $40 \%$ of patients with STD are treated in the private sector but the amount of self-treatment and traditional treatment is unknown. It is government policy to encourage and expand the tourist industry, and with a larger airport Colombo is likely to experience a great increase in tourists and other visitors. Sri Lanka has the nucleus of an excellent service for patients with sexually transmitted diseases which could be expanded to meet the growing demand that is likely to occur in the future. 